\title{
Escola na liquidez dos tempos: dilemas e desafios
}

\author{
Bruna Monize Rosalem Rodrigues* \\ Elisabeth Barolli**
}

\begin{abstract}
Resumo
A pesquisa de caráter qualitativo acompanhou o cotidiano de uma escola pública por dois anos. À medida que o trabalho de campo e a narrativa construída concomitantes à investigação se desenrolavam, diversos acontecimentos nos levaram a perguntar: que parâmetros estavam balizando a dinâmica dessa escola? A partir do conceito de pós-modernidade como tempos líquidos e as metáforas do jardineiro, guarda-caça e caçador, a nosso ver a escola era atravessada por um dilema intrínseco ao seu projeto de construir uma escola democrática: comportar ao mesmo tempo perspectivas de natureza incompatíveis. Ou seja, sustentar uma utopia em tempos líquidos. E mais, com uma estratégia que, em essência, reproduzia características desses mesmos tempos.

Palavras-chave: cotidiano escolar; práticas educacionais; tempos líquidos; utopia.
\end{abstract}

\section{Liquidity in the school of the times: challenges and dilemmas}

\begin{abstract}
The qualitative study followed the daily life of a public school for two years. As the field work and research constructed narrative unfolded, several events have led us to ask: what parameters were underlain the dynamics of this school? From the concept of postmodernity as liquid times, and the metaphor of the gardener, gamekeeper and huntsman, in our opinion the school was crossed by a dilemma intrinsic to his project of building a democratic school: include the same time prospects of nature incompatibles. That is, holding an utopian in liquid times. And further, with a strategy that essentially reproduced characteristics of those times.

Keywords: daily school; educational practices; liquid times; utopian.
\end{abstract}

\section{Introdução}

A escola é um lugar curioso, especialmente a escola pública. $\mathrm{O}$ que acontece em seu cotidiano, ou melhor, o que vem acontecendo nesse lugar na atualidade, desafia cada vez mais educadores e pesquisadores da área da Educação a reverem suas concepções sobre a função social que é atribuída à escola. Compreender as práticas escolares e as relações que se estabelecem entre os sujeitos que delas participam não tem sido tarefa trivial, sobretudo quando nos apoiamos em representações e ideais de uma escola que procurava responder a outra ordem cultural. Para podermos pensar a escola de hoje, há que se sujeitar às críticas vindas do movimento histórico-cultural que questiona os princípios que orientaram a constituição do que denominamos modernidade e propõe sua possível superação: a pós-modernidade. Surgem aí muitos dilemas que se impõem às nossas reflexões.

Nóvoa (2009) destaca uma visão de escola que, num passado não muito distante, cresceu como um "palácio iluminado", templo do saber. Atualmente, é possível dizer que a escola tornou-se apenas um polo - ainda que muito importante num conjunto de redes e de instituições que devem

* Endereço eletrônico: brosalem@gmail.com

** Endereço eletrônico: ebarolli@ gmail.com responsabilizar-se também pela educação das crianças e pela formação dos jovens. No entanto, a contemporaneidade exige que tenhamos a capacidade de recontextualizar a escola no seu lugar próprio, entender suas dinâmicas e refletir acerca de sua função social.

Em nossa investigação procuramos acompanhar, por cerca de dois anos, o cotidiano de uma escola pública municipal de ensino fundamental, na perspectiva de compreender sua dinâmica assumindo a ideia de cotidiano escolar como acontecimento, isto é, a escola como lugar em que se ensina e se aprende, onde se configuram diferentes relações entre os sujeitos praticantes deste cotidiano - alunos, professores, funcionários, gestão escolar -, bem como maneiras de fazer uma cultura própria, que caracteriza essa instituição como um espaço de ascensão e de reprodução sociais (Certeau, 2003). Em outras palavras, partimos do pressuposto de que a escola é construída socialmente em meio a uma trama de diferenças regionais, organizações sociais, comunidades locais, diferenças étnicas, que vão criando e organizando sua história.

Como considera Rockwell \& Ezpeleta (2007), essa história das práticas escolares, muitas 
vezes não documentadas, faz com que a escola ganhe vida através dos diálogos e narrativas de pesquisadores. A escola que acompanhamos e que denominamos "VR" era antiga na região. Tinha aproximadamente 40 anos de existência e na época (2009/2010) nela estudavam cerca de 800 alunos divididos em dois períodos: por volta de 380 alunos pela manhã e 420 à tarde. Existiam cerca de 35 professores, 15 no período da manhã abrangendo as disciplinas: História, Matemática, Português, Educação Física, Educação Artística, ERET (Educação, Relações Econômicas e Tecnologia), Inglês, Geografia, Ciências. A escola possuía 10 salas de aula e tinha, aproximadamente, 38 alunos por turma.

Durante o período de vivência na escola, foi possível observar que lá circulavam vários projetos e atividades extras que almejavam principalmente a criação de vínculos afetivos, a socialização entre os alunos e entre professores e alunos etc., tornando o ambiente da escola bastante movimentado. Grande parte dessas práticas era orientada pelo Tema Gerador e, sobretudo, pelos Jogos da Amizade. O Tema Gerador era escolhido pela comunidade escolar e era trabalhado de maneira transversal aos conteúdos das disciplinas durante um ano. $\mathrm{Na}$ época da pesquisa o tema foi "A arte de conviver". Já os Jogos da Amizade eram competições esportivas do qual participavam todos os alunos da escola, tanto os do fundamental I, quanto os do fundamental II. Cada time formado expressava um sentimento através de cores estampadas nas camisetas: Azul solidariedade, Verde cooperação, Laranja união e Preto respeito. Durante uma semana eram realizados jogos em diversas modalidades esportivas e uma disputa entre as torcidas. Ao final da semana, os times e as torcidas vencedoras eram premiados com medalhas e troféus.

Ao mesmo tempo presenciamos vários eventos que também faziam parte do cotidiano da escola "VR" e que nos despertaram provocações, incômodos e estranhamentos: o próprio ritmo com que a escola trabalhava os projetos e as atividades; alunos agredindo constantemente o patrimônio escolar e desrespeitando o trabalho dos professores; relações controversas entre alunos e professores dentro e fora da sala de aula; as soluções pouco eficazes da gestão com relação aos eventos de agressão ao patrimônio escolar e a inexistência de interdição a essas práticas dos alunos. Toda essa movimentação motivou-nos a perguntar: que parâmetros poderiam estar balizando a dinâmica dessa escola?
A nosso ver a escola procurava sustentar sua utopia de um projeto de escola democrática, concebido originariamente pela equipe gestora, por meio de estratégias que consideramos questionáveis quanto a sua pertinência para os fins requeridos. Como veremos ao longo deste trabalho, a escola parece não perceber que promover a participação pela participação implica resultados diferentes de promover uma participação comprometida com uma utopia.

\section{Procedimentos investigativos}

O cotidiano da escola "VR" foi acompanhado de uma perspectiva de observação participante apenas no período da manhã, quando estudavam alunos do $5^{\circ}$ ao $9^{\circ}$ ano do ensino fundamental, por meio de visitas regulares, de duas a três vezes por semana, durante cerca de dois anos. Nesse período procuramos conhecer os modos de viver da escola, o ritmo de suas movimentações cotidianas, captar idiossincrasias institucionais, bem como assuntos que circulavam nos diversos espaços, como pátio, refeitório, corredores, áreas externas da escola, o espaço de recepção dos alunos, a sala de professores, entre outros. Procuramos, assim, acompanhar a dinâmica da escola em diversas circunstâncias: nas reuniões de planejamento dos professores, do Conselho de Escola e de Pais e Mestres, na abertura dos Jogos da Amizade, na atividade promovida pela CPFL (Companhia Paulista de Força e Luz), na inauguração do Laboratório Interativo de Ciências, na reunião de final de semestre dos professores, na Festa Junina, entre outros. Foi possível, ainda, acompanhar algumas aulas, em particular, dos professores de Ciências, Geografia e Educação Física. Nesse percurso realizamos registros escritos e fotográficos.

O exercício de observação participante nos permitiu conversar mais informalmente com alunos, professores e equipe gestora e selecionar pontos de interesse que reclamaram pelo adensamento de informações. Assim, optamos por realizar entrevistas semiestruturadas com professores e equipe gestora para reavaliar a visão que estávamos formando daquele cotidiano escolar ou, ainda, retornar à observação de algumas situações já vivenciadas. Ao todo foi possível entrevistar seis professores: Ciências, Educação Física, Educação Artística, Inglês, Educação Especial e Geografia, de acordo com suas disponibilidades e duas das três integrantes da equipe gestora: a diretora $\mathrm{e}$ a 
orientadora pedagógica. As entrevistas tiveram duração de cerca de 50 minutos cada uma e, posteriormente, foram integralmente transcritas.

Ao mesmo tempo em que adentrávamos à vida da escola, fomos produzindo uma narrativa que buscava refletir o modo pelo qual a estávamos percebendo. À medida em que o trabalho de campo e a narrativa se desenrolavam, questionávamos diversos dos acontecimentos que a nosso ver marcavam e caracterizavam o espaço escolar. Em particular, fazíamos grande esforço para atribuir sentidos a um cotidiano escolar que a nosso ver mostrava-se controverso e de difícil compreensão.

\section{A escola, seu cotidiano e nossos estranhamentos}

A escola "VR" era provida de muitos recursos materiais e bem equipada em termos de espaços educativos (teatro, biblioteca, laboratório, sala de informática, horta, estufa, etc.), apresentava uma considerável infraestrutura que atendia alunos e professores e trabalhava com várias atividades e projetos.

Toda essa caracterização deixou transparecer uma escola bastante agitada, que não deixava espaço nem tempo para a monotonia. Em qualquer horário do período letivo, no caso as manhãs, vários alunos estavam fora das salas de aula fazendo outras atividades.

Professores pareciam sempre atarefados, compartilhando entre si ideias, projetos e atividades de cunho pedagógico, trazendo para o planejamento, ou mesmo para as conversas do diaa-dia, textos de pesquisas em Educação para discutir entre si. Alguns professores, inclusive, já haviam participado no período de realização da pesquisa de congressos em que haviam apresentado resultados do Projeto "Jogos da Amizade". Os professores demonstraram manter um bom relacionamento, pois formavam equipes de trabalho e ajudavam uns aos outros em projetos com os quais se identificavam. Nas salas dos professores, eles conversavam sobre vários assuntos, dividiam as despesas do café da manhã, comemoravam aniversários e saiam juntos.

A equipe gestora, constantemente, propunha reuniões entre os professores para discutir propostas de ensino e de avaliação, sugeria que os professores trabalhassem a partir de projetos e estava sempre aberta a novas ideias e sugestões de atividades pedagógicas. Era receptiva com pesquisadores e estagiários que desejavam fazer algum tipo de estudo na escola e também achava importante criar parcerias entre agências de fomento à pesquisa e instituições de ensino superior. A equipe gestora, na maior parte do tempo, estava atarefada com questões administrativas da escola, fazendo reuniões na prefeitura com a supervisora de ensino, resolvendo diversos conflitos entre os alunos, entre professores e alunos, entre pais e alunos. Davam orientações às famílias a respeito do desempenho e do comportamento dos seus filhos. Projetaram atender a solicitação dos pais para a colocação de câmeras nas áreas externas da escola que, para eles, teriam o objetivo de contribuir com a segurança dos filhos, bem como evitar que gangues ou os próprios alunos pichassem a escola. Porém, o projeto não se realizou durante o período em que estivemos na escola. Supervisionavam os espaços da escola na tentativa de garantir certa organização e de preservar o patrimônio escolar, que requeria constante atenção. Haviam pintado as paredes da escola duas vezes no ano para apagar as pichações, mas os alunos voltavam a pichar. As pichações percorriam, desde a entrada, os corredores, os tetos, os murais, os banheiros, as vidraças, até o chão (além de haver milhares de chicletes pisados). Havia pichações também em quase todo o mobiliário da escola, no anfiteatro, na biblioteca, na sala de informática, em portas, janelas e arquibancadas. Os únicos lugares que não estavam pichados eram o refeitório, a diretoria e a secretaria, a sala dos professores e o almoxarifado. Estranhávamos ver que existiam tantos espaços arborizados, plantas e árvores nativas, algumas até centenárias, jardim e horta, tudo tão sujo e entulhado de lixo. Nem mesmo a estufa escapava. Em boa parte da área onde ficavam as árvores havia embalagens, sacos plásticos, restos de comida, bolas de papel, garrafas pet e muitos outros resíduos espalhados no chão e dentro das salas de aula. Colocaram novas saboneteiras com álcool em gel para os alunos higienizarem as mãos, mas eles urinaram nos potes, o que levou a diretora decidir por retirá-las. Puseram papel higiênico nos banheiros, mas os alunos jogaram na privada, fizeram bolas de papel molhado e grudaram nos tetos ou saíram espalhando pela escola. A diretora, então, optou por não mais colocar papel higiênico nos banheiros. Instalaram vidros novos na porta de entrada da recepção da escola, mas os alunos arrebentaram, então colocaram outra vidraça. Por diversas vezes precisaram refazer os murais em que os alunos publicavam seus trabalhos, com novas placas de papelão para cobrir os rasgos que os próprios alunos faziam. Estranhávamos essa maneira com que a gestão da escola procurava 
resolver as questões ligadas à conservação do patrimônio escolar, pois nos parecia que ela procurava resolver de maneira local problemas que nos pareciam globais. A nosso ver eram soluções paliativas, mas que iam se configurando como permanentemente temporárias. Estranhávamos também o fato de que parecia não haver interdição para as práticas dos alunos.

De acordo com os professores, os alunos, de modo geral, eram participativos, criativos, com potencial, apresentavam bom desempenho, sobretudo nas atividades extra-classe. Porém, também os consideravam preguiçosos, imaturos, "diamantes brutos" que precisavam ser lapidados. Afirmavam, enfaticamente, que para eles era uma tarefa difícil controlar os alunos durante as aulas e fazer com que eles prestassem atenção no conteúdo das disciplinas e completassem as tarefas. A orientadora pedagógica nos relatou que realmente o desempenho dos alunos nas disciplinas não estava caminhando como a gestão escolar esperava:

Saberes do $1^{\circ}$ semestre, todas as classes, todas as disciplinas... nós não temos, assim, nenhuma classe que você fala: "olha essa classe teve uma aprendizagem em todas as disciplinas plenamente satisfatória, ultrapassou - vou chamar de valor numérico que fica mais fácil - os 50\%, todos os alunos ultrapassaram, estão de satisfatório para mais". Nós não tivemos isso, nós trabalhamos com gráficos, com mapas e realmente revelou isso; incomodou.

Quando pudemos acompanhar presencialmente algumas aulas ou mesmo circular pelos corredores víamos a dificuldade dos professores ao conduzirem suas aulas. A algazarra dos alunos, a pouca disponibilidade e interesse em participar das aulas nos remetia à ideia de que os alunos não respeitavam o trabalho dos professores e que pouco importavam-se com eles. Embora as turmas não fossem tão grandes, alguns professores chegavam a utilizar microfones para poder lecionar. De modo geral, os alunos mostravam-se muito pouco disponíveis a ouvir os professores; o que o professor sabia e tinha a transmitir parecia ter pouco valor. Como os professores não podiam mais reprovar os alunos (regime de progressão continuada), muitos estudantes zombavam desta situação recusando-se a fazer as tarefas que o professor pedia ou mesmo chegavam ao ponto de fingir que estavam fazendo-as como aconteceu numa aula de Ciências em que o professor propôs uma atividade para observar o crescimento de uma semente de feijão. Nesta atividade os alunos fingiram plantar a semente no vaso e continuavam regando-a como se tivesse sido plantada. Às vezes, o professor não conseguia iniciar sua aula ou não conseguia terminar o que havia planejado para um determinado dia, porque os alunos estavam dispersos, desinteressados, preocupados com outros tipos de assuntos. Porém quando os alunos encontravam os professores nos corredores pareciam ser "os melhores amigos". Interessavamse pelo que os professores tinham a dizer e interagiam com os assuntos que surgiam neste meio tempo. Mostravam-se contentes quando os encontravam em outros espaços, como o corredor, e começavam a conversar sobre diversos assuntos de suas vidas: o filme que acabaram de ver no fim de semana, o novo instrumento musical que estavam praticando, se a família ia bem, que tipo de carro o professor mais gostava, e assim por diante. Parecia que os alunos consideravam os professores mais como amigos do que como mestres.

Era comum ver as tentativas de fuga dos alunos com relação às aulas e às tarefas, embora permanecessem na escola. Gostavam de ficar perambulando entre as árvores, conversando e brincando com os colegas, fazendo qualquer outra atividade desde que não fosse tarefa escolar. A sensação era a de que os alunos desvalorizam seus próprios trabalhos quando os rasgavam nos murais, e cultivavam uma prática de pouco respeito ao patrimônio escolar. Os professores conviviam com essas práticas dos alunos com relação ao patrimônio escolar e muitos buscavam justificar de alguma forma as atitudes dos estudantes.

A equipe docente apreciava e ficava animada com a abertura que a gestão concebia para o desenvolvimento de atividades extras como competições, gincanas, projetos culturais e esportivos voltados à socialização dos alunos. Eram tantas práticas que conviviam naquela escola, que para nós parecia não haver tempo para realmente refletir sobre elas; "ruminar", "digerir"... O ambiente escolar mostrava-se tão intenso e agitado, que por muitas vezes era possível confundir-se sobre que tipo de projeto ou atividade os estudantes estavam participando em um determinado momento.

Os professores valorizavam transmitir aos alunos outros conhecimentos que não estavam, 
necessariamente, vinculados ao planejamento de ensino do conteúdo da disciplina, mas que, ao mesmo tempo, estavam relacionados a valores como a cidadania e o respeito à diversidade, e à formação de um cidadão crítico e integrado com o mundo:

Eu fiz um projeto em 2008, que eu trabalhei com duas professoras, uma de Educação Especial e outra de Ciências, a gente trabalhava sexualidade. A gente falava de música, sobre namoro, eles que trazem o tema para a gente discutir na aula, foi muito legal, a gente saiu para ir ao cinema, assim, extrapolou a relação de sala de aula e professor. [...] Trabalhei certa vez com diário. Uma vez por semana eles tinham que escrever e trazer na outra semana o que eles escreveram sobre um fato que aconteceu na semana e aí a gente discutia isso. Quer dizer, você está trabalhando a vida do indivíduo, trabalhando os sentimentos dele, o relacionamento pais $e$ filhos, o relacionamento de amizade, isto é uma coisa muito dinâmica. (Professora de Ciências)

Acho que tudo que é feito que tenha uma disciplina, uma regra, aprender, nem que for abrir um livro e usar o dicionário, qualquer coisinha que você ensina, eu acho que você está lucrando com aquilo. (Professora Inglês)

Quando eu dou um conteúdo pra eles, esse é o meu modo de dar exemplo pra eles, com o diálogo, é também um modo de cidadania, de política que vai levar pra vida deles. [...] As minhas atitudes ensinam também, a cidadania, a ética, o relacionamento social, [...] vamos dizer, que o conteúdo é a interação, aluno e aluno, aluno e professor. (Professora de Educação Física)

Não é só pra fazer uma lição, é trazer um pouco de cultura. [...] É a formação do aluno, não é só passar o conteúdo, é desenvolver o aluno, sua criatividade, sua imaginação, deixar o aluno mais crítico. (Professora de Educação Artística)

Estranhamos muito o fato de que mesmo a escola trabalhando com diversos projetos que priorizavam a convivência harmônica entre alunos e entre estes e a instituição escolar, como o Tema Gerador e os Jogos da Amizade, a relação dos alunos com o patrimônio escolar e com os professores permaneceu praticamente invariável durante o período da pesquisa. Ou seja, a nosso ver havia um descompasso entre o que a gestão escolar pretendia e o que vivenciávamos no cotidiano da escola.

Assim, como já mencionado, a escola "VR" mostrava-se a nossos olhos como uma escola controversa e muito difícil de ser compreendida. Perguntávamos: que parâmetros orientam suas práticas?

Em toda nossa trajetória de vida de estudantes e de pesquisadores, construímos projeções que configuraram certo modelo de escola, de instituição de ensino, de ambiente de estudo. Ao longo do período em que participamos do cotidiano da escola "VR", sua dinâmica foi nos causando alguns estranhamentos. E é possível de se estranhar, pois os parâmetros oriundos de uma visão moderna de escola e de ensino que construímos parecem não mais nos servir de referência para compreender as escolas de hoje, ou pelo menos, a escola investigada.

Para compreender as maneiras de ser dessa escola, o lugar que ela ocupa na contemporaneidade e dar sentido aos nossos estranhamentos foi necessário nos afastarmos de muitas de nossas crenças que, de modo geral, assentavam-se numa visão de escola típica da modernidade.

Consideramos que um dos grandes desafios do pesquisador que vai a campo é manter em suspenso, dentro do possível, sua memória e seu desejo, esforçando-se num exercício de estranhamento que lhe permite experimentar novos caminhos de interpretação e de compreensão de situações que a princípio lhe seriam familiares. Em outras palavras, é o desafio de buscar ultrapassar os estereótipos e as normatividades, tentando compreender as singularidades e as diferenças de um determinado universo social.

$\mathrm{O}$ estranhamento permite, ainda, que o pesquisador possa atingir patamares sofisticados de análise de seus dados, uma vez que ao manter em suspenso suas próprias experiências, sensações, modelos e estruturas (ideológica, sociais, psicológicas), tem a oportunidade de desnaturalizar o campo de pesquisa em que está inserido e alcançar novas possibilidades de interpretação (Dauster, 2003). Em acordo a essa perspectiva, buscamos neste trabalho não cair no conforto da interpretação normativa, de uma leitura informada demais, que 
leva a conclusões do tipo: "se a escola não está seguindo os 'padrões' que configuram um ambiente de estudo típico da modernidade, então essa instituição está perdida, fadada ao fracasso". Nosso esforço concentrou-se na tentativa de compreender o que esta instituição poderia nos dizer e como ela se situa na atual ordem cultural em que se encontra.

\section{Pós-modernidade e tempos líquidos}

Em oposição ao "tempo sólido", o "tempo líquido" aponta para uma condição em que as instituições que asseguravam a rotina e firmavam padrões de comportamento e de vida profissional, já não se mantém por muito tempo. As regras são dissolvidas pela própria dinâmica das relações e dos interesses ditados pelas formas de consumo em sua maneira mais ampla (consumo de ideias, bens materiais, modismos, cultura) e pela busca permanente de uma identidade que não pode ser fixa, ser firme, ser estruturada, para que essa nova identidade não necessite de responsabilidade e de vigilância (Bauman, 2007).

A vida em movimento frenético nos desafia a lidar com a inconstância dos padrões antes tradicionais, surgindo outros modelos e padrões de ser e de estar, obrigando a incorporação de novas habilidades, novos saberes para se adequar à liquidez do tempo. Esse movimento convida a não nos fixarmos, a não mantermos compromissos a longo prazo, não nos prendermos a lugar nenhum por mais agradável que esteja, não termos uma só vocação, não jurarmos coerência e lealdade a nada e a ninguém, não guardarmos esforços para o futuro e nem nos reportarmos a experiências passadas, pois não constituem referências. Sem mais direções, o tempo já não estrutura o espaço, não há "para frente" ou "para trás" o que importa é a destreza de se adequar às situações, exercitar a capacidade de se mover e não ficar parado, assimilando diversas e breves experiências quando elas chegam (Ibid).

$\mathrm{Na}$ escola "VR" prevalecia uma espécie de dinâmica em que muitas atividades aconteciam ao mesmo tempo: alunos e professores não podiam ficar parados e diversas práticas, que se traduziam no desenvolvimento incessante de parcerias com empresas e universidades, projetos de socialização, atividades extras para o exercício da criatividade, transitavam naquele cotidiano preenchendo todo seu espaço em um curto período de tempo. Os saberes escolares se mesclavam o tempo todo com outros tipos de saberes que eram projetados para dentro da escola. A nosso ver, toda essa movimentação nos indicava que a escola vivia a realidade dos tempos líquidos.

Ao mesmo tempo, diversas evidências também marcavam outros movimentos e práticas da escola. Por um lado buscava-se valorizar o ensino dos conteúdos disciplinares, fazer uso de vigilância através de câmeras e a instalação de diversos dispositivos de controle, como os de entrada e saída dos alunos no corredor; dar conta das transgressões dos alunos em relação às aulas e à conservação do patrimônio escolar, dos conflitos que giravam em torno do próprio trabalho da gestão e do esforço dos professores e da equipe gestora em adaptar o processo educativo à fase adolescente dos alunos. Por outro lado buscava-se constituir uma escola contemporânea regulada pela participação democrática, bem como pela criação de vínculos afetivos entre alunos e entre professores e alunos. $\mathrm{Ou}$ seja, parecia tentar construir uma utopia, sustentada por novas maneiras de conduzir as práticas educacionais.

\section{Guarda-caças, jardineiros e caçadores}

O pensamento utópico nasceu com a modernidade, projetando olhares otimistas para o mundo (Bauman, 1998). Para nascer o sonho dos utopistas era preciso desejar irresistivelmente, mas de maneira difusa, um mundo outro, que funcionasse de outra forma, que pudesse ser consertado, "começando do zero". Segundo Bauman (2009), para que a utopia nasça é preciso duas condições: que haja uma forte sensação de incômodo com uma determinada realidade no mundo e que esta, por sua vez, deva ter seus fundamentos revistos no intuito de reajustá-la. A outra condição é a existência de uma confiança no potencial transformador do ser humano, uma crença que está articulada com a racionalidade capaz de perceber que algo está errado, saber o que precisa ser modificado e ter coragem e força para enfrentar as situações problemáticas e extirpá-las. Em resumo, para viver a utopia e levá-la adiante é preciso potencializar as atitudes para o atendimento das necessidades humanas vividas ou ainda se "preparar" para futuras necessidades.

Bauman (2007) metaforiza que a postura pré-moderna em relação ao mundo era próxima à atividade de um guarda-caça, e a visão moderna se aproximava da função de um jardineiro.

A principal tarefa de um guarda-caça é defender a terra contra a interferência humana, a fim de proteger o "equilíbrio natural", manter as coisas 
como estão, evitar que ocorra um desvirtuamento da ordem vigente. O trabalho do guarda-caça é sustentando pela crença de que as coisas andam melhor quando não as consertamos; o mundo é uma cadeia divina de seres em que cada um tem seu lugar útil e legítimo.

O jardineiro já parte do princípio de que não há uma determinada ordem no mundo (ou pelos menos no território que está sob seus cuidados), se não fosse pela sua vigília constante. $\mathrm{O}$ jardineiro sabe que tipos de plantas devem crescer ou não em seu jardim. Primeiro ele imagina como seria um lote desejável e harmônico e depois trabalha para que essa imagem se reproduza no pequeno terreno (Bauman, 2007). São os jardineiros os mais hábeis na construção de utopias. É na imagem do ideal, do desejável, da harmonia que os jardineiros projetam o terreno utópico.

Se na atualidade ouve-se falar em "morte da utopia", do "desvanecimento da imaginação utópica", é porque os jardineiros estão cedendo cada vez mais à posição de caçadores, outra metáfora proposta por Bauman (2007) para se referir à postura pós-moderna em relação ao mundo. Os caçadores não dão a mínima para o "equilíbrio das coisas", seja natural ou planejado, estão mais preocupados em começar uma nova "matança", sem cogitar que os animais da floresta podem diminuir ou acabar, pois podem muito bem se aventurar em outras florestas e novamente encher suas sacolas.

\section{$O$ dilema da escola "VR": a guisa de conclusão}

Quando começaram a trabalhar na escola "VR" em 2003, a diretora e a orientadora pedagógica nos contaram que a comunidade escolar - pais, funcionários e parte dos professores - estava "presa" em uma visão tradicional de Educação. Isto é, segundo elas, acreditava-se que para garantir um bom trabalho de gestão escolar era preciso impor regras com relação à disciplina dos alunos e adotar uma postura rígida, ou seja, a equipe gestora teria que ser vista pela comunidade como uma espécie de "general" que controla as ações de professores e alunos, que deveria resolver qualquer tipo de problema e que não poderia abrir tanto espaço para a participação da comunidade escolar na gestão da escola.

No entanto, a equipe gestora tinha outro projeto: construir ao longo de seu trabalho uma escola participativa em que o diálogo fosse o grande organizador da dinâmica do cotidiano escolar e das relações entre alunos, professores e a própria gestão.
Nas palavras da diretora é possível perceber essa busca por uma nova identidade para a escola:

Eu peguei uma escola que tinha alguns vícios, ela era considerada tradicionalmente a melhor escola do bairro, uma das melhores da cidade, com pessoas que tinham alguns ranços pedagógicos $e$ administrativos. Foi duro para mudar, tinha concepções muito antigas $e$ tradicionais. [...] A gente [gestão] ia chegando e trazendo nossa identidade, desmontando aquelas concepções, e até hoje eu não consigo desmontar na minha equipe, porque você tem que ir aos poucos. Eles [funcionários e alguns professores que já trabalhavam na escola] são muito saudosistas, eles falam "a diretora que eu tinha aqui há vinte anos chegava e batia as portas, ela gritava, ela fazia os funcionários ajoelharem no chão pra fazer a limpeza", então chega alguém com esse projeto de diálogo em que o funcionário participa, gente constrói coisas, funcionários com funcionários da gestão, a integração, a gente constrói coisas, eu não estou aqui pra fazer ninguém ajoelhar. (Diretora)

Assim, aproveitando as metáforas de Bauman, compreendemos que a escola, representada, sobretudo, pela equipe gestora, posicionava-se como o jardineiro que para cuidar de sua utopia dedica atenção constante às culturasjardins, pois um momento de negligência ou mera distração as fariam retornar ao estado do qual surgiram.

Sem dúvida, é possível afirmar que, de modo geral, gestão e professores empenhavam-se para dar conta dos projetos assumidos. Reconheciam, inclusive, que estavam diante de uma tarefa árdua que requeria muito esforço para ser concretizada, como já enfatizava a diretora: "a gestão participativa é dolorosa, você tem que ter muita personalidade, porque você é testada o tempo todo". Para realizar o desejo de construir uma escola participativa, de priorizar o diálogo como grande organizador, a escola abria-se para diversos projetos de socialização que, em essência, pretendiam que todos estivessem constantemente envolvidos com alguma atividade. Configurou-se, assim, a própria dinâmica da escola e a maneira pela qual a instituição escolheu para conduzir a tarefa de educar e de formar seus estudantes. Aproveitando as 
palavras da orientadora pedagógica, diríamos que esta parece ter sido a principal estratégia da gestão para sustentar sua utopia:

estamos caminhando, é uma escola sempre com movimento, sempre construindo alguma coisa, não é uma escola que você vem aqui, "nossa tá tudo paradinho"; não é a característica desta escola, ela é puro movimento, o tempo todo, é assim que nós estamos aprendendo e buscando uma escola de qualidade, uma escola democrática. Aqui os alunos produzem, os professores até diriam que se a organização fosse outra os alunos produziriam muito mais, aprenderiam muito mais. É uma característica da equipe gestora, não queremos uma escola com um projeto básico de escola disciplinadora, uma escola que regula as ações, muito pelo contrário, o que essa gestão chama de indisciplina é lidar com esse conflito de permitir a participação de todos com respeito, $e$ muitas vezes pra conseguir essa participação de todos é o movimento que você tá vendo aí, pra alguns isso é pura indisciplina. [...] A gestão busca isso mesmo, uma educação transformadora, uma educação de qualidade, mas nessa configuração, de participação [...].

Os conflitos vividos pela escola, e reconhecidos por todos seus educadores, eram muitos e em boa parte decorrentes dessa estratégia. Se, por um lado, a gestão e a maioria dos professores compartilhavam com a perspectiva de uma escola democrática, bem como com essa maneira de construí-la, alguns professores e familiares dos alunos opunham-se, numa postura que se aproximava da figura do guarda-caça, ao exigir que a escola restabelecesse os princípios de uma escola tradicional.

Há que se considerar, ainda, que outros pais gostariam que a escola preparasse seus filhos para serem caçadores eficientes. Nesse sentido, o fato de quererem que a escola tornasse os alunos disciplinados, não seria para atender, necessariamente à moral da sociedade moderna, mas sim para que o conhecimento, entendido enquanto um objeto que pode ser útil aos seus filhos, viesse a gerar resultados na vida prática. Nesse caso, não é o conhecimento pelo conhecimento que parece importar tanto, mas sim o conhecimento como algo proveitoso que pode ser descartado tão logo seus filhos viesse a se tornar bons caçadores.

Parece que parte dos alunos da escola respondia a essa demanda característica de nossa sociedade que vive em tempos líquidos. A história do feijão, por exemplo, aquele evento em que os alunos, na aula de Ciências, fingiam que plantavam a semente no vaso, mas continuavam regando uma planta inexistente, parece se constituir numa metáfora que, de certa forma, indica uma negação quanto ao próprio desenvolvimento, ou ainda, ao descomprometimento dos alunos com relação à sua formação futura. Assim, aproveitaram a aula de forma eventual e passageira, como mais uma oportunidade para se divertirem durante o período escolar. Nesse episódio eles mais se assemelharam à figura de caçadores, ou seja, exploraram a situação para o que ela lhes oferecia no momento em termos de satisfação imediata.

Porém, não podemos deixar de considerar que as escolas sempre serão atravessadas por conflitos de diversas naturezas que tem origem justamente no encontro de suas escolhas pedagógicas com as demandas de pais, alunos, professores, políticas públicas, etc.. O que mais gostaríamos de chamar a atenção neste trabalho é para o dilema vivido pela escola "VR", que, a nosso ver, é intrínseco à maneira pela qual vinha conduzindo e sustentando seu projeto de escola democrática: comportar num só momento histórico perspectivas que por sua natureza são incompatíveis. Ou seja, sustentar uma utopia em tempos líquidos. E mais, com uma estratégia que, em essência, reproduz características desses mesmos tempos.

Não basta querer articular a formação dos estudantes a partir do diálogo, sem criar mecanismos de institucionalizar essa ideia. Apesar de o diálogo, a princípio, ser o organizador das relações lá vividas, não tinha, até então, se incorporado de maneira efetiva na dinâmica daquele cotidiano. A gestão e a maioria dos professores cediam às demandas dos tempos líquidos, sobretudo na ideia da participação pela participação, ou seja, a participação política muitas vezes parecia estar sendo substituída pela participação social. A participação política requer compromisso com ideais, com utopias; já a participação social, em geral, é baseada num voluntarismo. Nesse ponto, parece que a escola estava compreendendo de forma igual movimentos que são diferentes. Até que ponto a comunidade escolar refletia sobre a necessidade 
de haver o diálogo? O diálogo não se estabelece em si mesmo, não poderia ser colocado como meta última, mas como meio para se alcançar outras propostas e ações na escola. Nesse sentido, diríamos que a utopia estava estrategicamente mal concebida. Em nossa interpretação, a gestão precisaria abrir um espaço de reflexão junto à comunidade escolar sobre o sentido e a direção de seu projeto em sua totalidade e perceber que fazendo isso poderia criar possibilidades de nutrir sua utopia e sustentar a vida da instituição.

De fato, a escola enfrenta dificuldades legítimas em desejar sustentar uma utopia em tempos líquidos, e muitas das soluções que vinha implementando mostraram-se de pouca ajuda. Acreditávamos inicialmente que a escola como um todo havia naturalizado os episódios que considerávamos de agressão à estrutura física e ao ambiente da escola, ao seu mobiliário e aos professores, principalmente em função das soluções por ela implementadas: não colocar mais álcool gel, nem papel higiênico nos banheiros, substituir um papelão atrás do outro nos murais etc.. Porém, com base nas elaborações de Bauman, pudemos rever essa interpretação. Não nos parece que era necessariamente uma questão de naturalização, mas sim a percepção e o incômodo da gestão, ou mesmo de alguns professores em enfrentar a dificuldade de sustentar uma utopia em tempos líquidos. Em outras palavras, parece-nos que era uma forma da gestão negar as circunstâncias, ou seja, o fato de que os alunos em muitos momentos aproximavam-se da metáfora de caçadores. Cada vez que esses eventos aconteciam, colocavam para a gestão quase que a impossibilidade da sua utopia; as soluções encontradas funcionavam, então, como uma forma de apagamento daquilo que era incompatível ou conflitante com a utopia da escola.

Ao final ficamos com a pergunta: como a escola "VR" poderia manter sua utopia em tempos líquidos? A resposta a esta questão não é trivial, mas nossa reflexão nos permite sugerir a necessidade da escola rever as estratégias pelas quais vinha conduzindo sua utopia, isto é, seu projeto de escola democrática. E parece que é nesse ponto que ela encontra sua maior dificuldade, e talvez esse seja seu grande desafio: criar e sustentar uma utopia que vá além da participação pela participação, do diálogo pelo diálogo, da amizade pela amizade.

\section{Referências}

BAUMAN, Zigmund. O mal-estar da pósmodernidade. Rio de Janeiro: Jorge Zahar, 1998.

Zahar, 2007.

Tempos líquidos. Rio de Janeiro:

Entrevista Bauman. Disponível em www.revistacult.uol.com.br/home/2010/03/entreviszygmunt-bauman/ Acesso em: 22/01/2012.

CERTEAU, Michel. A Invenção do Cotidiano: Artes de Fazer. 9a. Edição. Petrópolis: Editora Vozes, 2003.

DAUSTER, Tânia. Um saber de fronteira - entre a Antropologia e a Educação. $\mathbf{2 6}^{\circ}$ Reunião Anual da ANPED: Mesa Redonda: As Ciências Sociais e a Pesquisa em Educação. Disponível em: www.anped.org.br/reunioes/26/outrostextos/setania dauster.doc. Acesso em: 6/12/2011

NÓVOA, Antônio. Professores: imagem do futuro presente. Instituto de Educação. Universidade de Lisboa. Educa, 2009

ROCKWELL, Elsie; EZPELETA, Justa. A Escola: Relato de um processo inacabado de construção. Revista Currículo sem Fronteiras. v.7, n.2, Jul/Dez 2007, p. 131-147, Disponível em: http://www.curriculossemfronteiras.org/>. Acesso em: $12 / 04 / 2010$.

\section{Sobre as autoras:}

Bruna Monize Rosalem Rodrigues: Pedagoga formada pela Universidade Estadual de Campinas (2007), Mestre em Educação pela Universidade Estadual de Campinas (2012).

Elisabeth Barolli: Possui Bacharelado (1978) e Licenciatura em Física pela Universidade de São Paulo (1979), Mestrado em Ensino de Ciências (Modalidade Física e Química) pela Universidade de São Paulo (1989) e 
Doutorado em Educação pela Universidade de São Paulo (1998). Atualmente é Professor Assistente-Doutor da Universidade Estadual de Campinas.

Recebido em 25/12/2012

Aprovado em 07/03/2014 